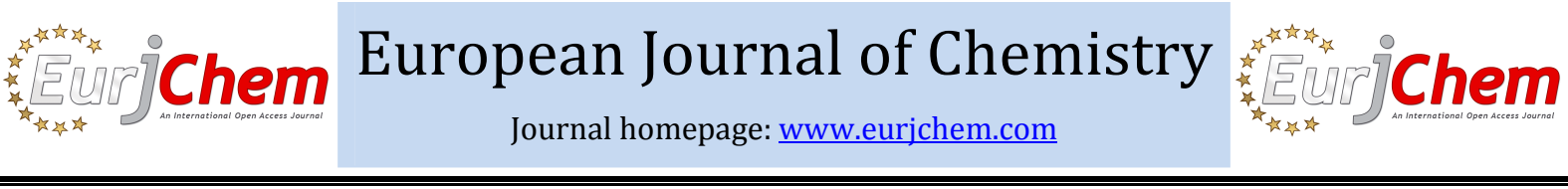

\section{Synthesis and characterization of novel heterocycles based on tetrazine and hydrazonoyl halides}

\author{
Abdelwahed Rashad Sayed a,b,*, Shar Saad Al-Shihry a and Mohsen Abdel-Motaal Gomaa a,c \\ a Department of Chemistry, Faculty of Science, King Faisal University, Hofuf, 31982, Saudi Arabia \\ b Department of Chemistry, Faculty of Science, University of Beni Suef, Beni Suef, 62511, Egypt \\ c Department of Chemistry, Faculty of Science, University of Minia, Minia, 61519, Egypt \\ ${ }^{*}$ Corresponding author at: Department of Chemistry, Faculty of Science, King Faisal University, Hofuf, 31982, Saudi Arabia. \\ Tel.: +966.3.561009338. Fax: +966.3.5886437. E-mail address: arsayed@kfu.edu.sa (A.R. Sayed).
}

\section{ARTICLE INFORMATION}

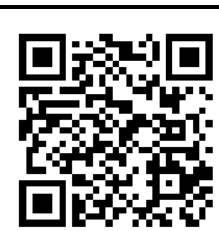

DOI: $10.5155 /$ eurjchem.5.2.267-271.913

Received: 01 September 2013

Received in revised form: 12 October 2013

Accepted: 12 October 2013

Online: 30 June 2014

\section{KEYWORDS}

\begin{tabular}{l}
\hline Triazole \\
Pyrazole \\
Tetrazine \\
Bismalimide \\
Thiohydrazonate \\
Hydrazonoyl halides \\
\hline
\end{tabular}

\section{Introduction}

1,2,4,5-Tetrazine is a strongly colored (red) molecule which is planar [1]. S-Tetrazines have been studied for several decades because their spectroscopic and photo dissociation properties lend themselves to modeling. Tetrazines are highly reactive for aromatic compounds, forming cycloaddition compounds. 1,2,4,5-Tetrazines with a large variety of substituents in the 3- and 6-positions of the heterocyclic are easily accessible, and due to their potential role in inverse-type DielsAlder reactions, members of this heterocyclic class have found widespread use in many fields of organic chemistry [2]. The pyridazine nucleus is of considerable interest because of its synthetic applications [3-5], and important pharmacological activities [6,7], most of them related to the cardiovascular system $[8,9]$.

The interest in the chemistry of hydrazonoyl halides is a consequence of the fact that they undergo a wide variety of reactions which provide routes to many of heterocyclic compounds [10-13].

The 1,3-dipolar cycloaddition, also known as the Huisgen cycloaddition [14], is a classic reaction in organic chemistry consisting of the reaction of a dipolarophile with a 1,3-dipolar compound that allows the production of various five membered heterocycles. Most of dipolarophiles are alkenes, alkynes and molecules possessing related heteroatom functional groups. A survey of literature revealed that pyrazoles belong among the most representative fivemembered heterocyclic systems [15].

We report herein a convenient and efficient synthesis of new heterocycles based on tetrazine and hydrazonoyl halides.

\section{Experimental}

\subsection{Instrumentation and chemicals}

All the chemicals were purchased from Aldrich and Fluka, and used without further purification. Melting points were measured on an electrothermal Gallenkamp melting point apparatus and are uncorrected. The ${ }^{1} \mathrm{H}$ and ${ }^{13} \mathrm{C}$ NMR spectra were recorded in DMSO- $d_{6}$ with tetramethylsilane (TMS) as an internal standard using $300 \mathrm{MHz}$ Varian Gemini spectrometer. The IR spectra were measured on a Fourier Transform and Pye Unicam Infrared spectrophotometers using potassium bromide wafer. Mass spectra were recorded on a GC/MS-QP 1000 EX spectrometer at an ionizing potential of $70 \mathrm{eV}$. Elemental microanalyses were carried out at the Microanalytical Center of Cairo University, Giza, Egypt. 


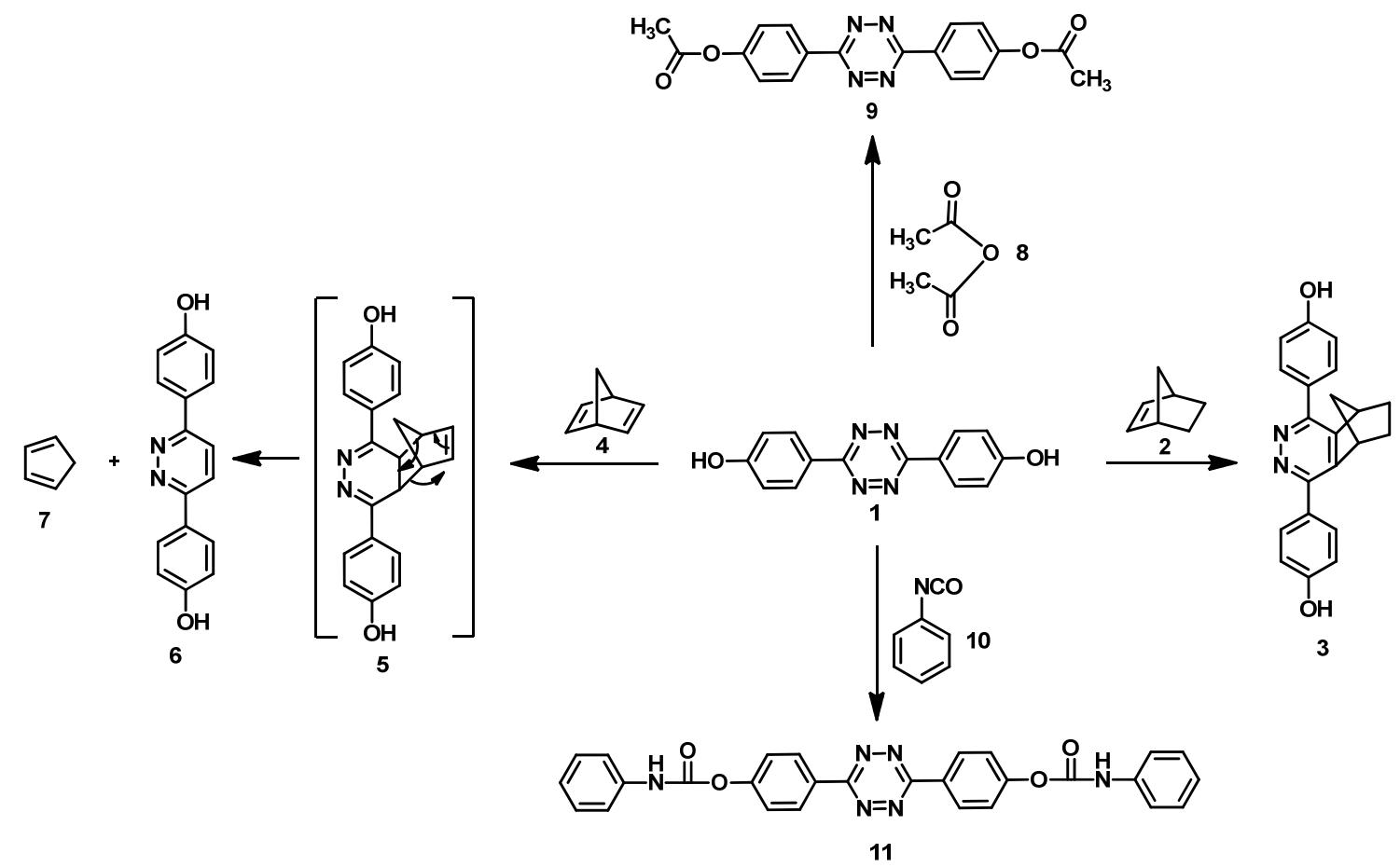

Scheme 1

The identification of compounds from different experiments were secured by mixed melting point's and super imposable IR spectra.

The starting reagents $\mathbf{1}$ [16], 12 [17], 15 [18], 16 [19], 20 [20], 21 [21], and 25 [22] were prepared as previously described.

\subsection{Synthesis}

\subsubsection{Synthesis of 4,4'-((5R,8S)-5,6,7,8-tetrahydro-5,8- methanophthalazine-1,4-diyl)diphenol (3) and 4,4'- (pyridazine-3,6-diyl)diphenol (6)}

To a dry $100 \mathrm{~mL}$ round-bottom flask were charged 3,6-bisphenolyl-1,2,4,5-tetrazine (1) (2.66 g, $10 \mathrm{mmol})$ and bicycle [2.2.1] hept-2-ene (2) or bicyclo[2.2.1]hept-2,5-diene (4) (10 mmol) in DMF at room temperature. The solution were stirred, the progress of reaction was monitored by disappear of red color and TLC, when the reactions were stopped and DMF was removed. The final separation of the products dried and recrystallized from DMF-MeOH $(5: 15, v: v)$ to give the final products (Scheme 1 ).

4,4'-((5R,8S)-5,6,7,8-Tetrahydro-5,8-methanophthalazine1,4-diyl)diphenol (3): Color: Pale Yellow. Yield: 92\%. M.p.: > 350 ${ }^{\circ} \mathrm{C}$. FT-IR (KBr, v, cm-1): $3219(\mathrm{OH})(\mathrm{br}$, phenol), $1612(\mathrm{C}=\mathrm{N})$ (pyridazine), $1601(\mathrm{C}=\mathrm{C})$ (unsaturated). ${ }^{1} \mathrm{H}$ NMR $(300 \mathrm{MHz}$, DMSO- $d_{6}, \delta$, ppm): 1.42-1.83 (q, 4H, $\left.\mathrm{CH}_{2}\right), 2.21\left(\mathrm{~d}, 2 \mathrm{H}, \mathrm{CH}_{2}\right), 3.68$ (p, 2H, CH), 7.12 (d, 4H, J = $9 \mathrm{~Hz}, \mathrm{Ar}-\mathrm{H}), 7.71$ (d, $4 \mathrm{H}, J=9 \mathrm{~Hz}, \mathrm{Ar}-$ $\mathrm{H}), 10.53$ (s, 2H, OH). ${ }^{13} \mathrm{C}$ NMR (75 MHz, DMSO- $\left.d_{6}, \delta, p p m\right)$ : 24.4, 43.3, 50.1, 116.2, 122.1, 131.4, 152.1, 152.2, 160.9. MS (EI, $m / z(\%)): 330\left(\mathrm{M}^{+}, 79\right)$. Anal. calcd. for $\mathrm{C}_{21} \mathrm{H}_{18} \mathrm{~N}_{2} \mathrm{O}_{2}: \mathrm{C}, 76.34 ; \mathrm{H}$, 5.49; N, 8.48. Found: C, 76.29; H, 5.50; N, 8.46\%.

4,4'-(Pyridazine-3,6-diyl)diphenol (6): Color: Green. Yield: 96\%. M.p.: > 300 \%C. FT-IR (KBr, v, cm-1): $3138(\mathrm{OH})(\mathrm{br}$, phenol), $1608(\mathrm{C}=\mathrm{N})$ (pyridazine), $1593(\mathrm{C}=\mathrm{C})$ (unsaturated). ${ }^{1} \mathrm{H}$ NMR (300 MHz, DMSO-d6, $\left.\delta, \mathrm{ppm}\right): 6.68$ (d, $4 \mathrm{H}, J=9 \mathrm{~Hz}, \mathrm{Ar}-$ $\mathrm{H})$, 7.95-8.18 (m, 6H, Ar-H), 10.02 (s, 2H, OH). ${ }^{13} \mathrm{C}$ NMR (75 MHz, DMSO-d6, $\delta, \mathrm{ppm}): 116.1,124.0,126.3,128.4,156.3$,
159.9. MS (EI, $m / z(\%)): 264\left(\mathrm{M}^{+}, 61\right)$. Anal. calcd. for $\mathrm{C}_{16} \mathrm{H}_{12} \mathrm{~N}_{2} \mathrm{O}_{2}$ : C, 72.72; H, 4.58; N, 10.60. Found: C, 72.69; H, 4.62; N, $10.58 \%$.

\subsubsection{Synthesis of $(1,2,4,5$-tetrazine-3,6-diyl)bis $(4,1-$ phenylene) diacetate (9)}

In $50 \mathrm{~mL}$ of acetic anhydradide $8(20.4 \mathrm{~g}, 0.2 \mathrm{~mol}), 3,6$-bis phenolyl-1,2,4,5-tetrazine (2.66 g, $0.01 \mathrm{~mol}) \mathbf{1}$ is refluxed for 5 $\mathrm{h}$ at $140{ }^{\circ} \mathrm{C}$. The mixture was cooled; the solid filtered and washed will with methanol, recrystallized from DMF to give final product 9 (Scheme 1$)$.

(1,2,4,5-Tetrazine-3,6-diyl)bis(4,1-phenylene) diacetate (9): Color: Violet. Yield: 94\%. M.p.: > $300{ }^{\circ} \mathrm{C}$. FT-IR (KBr, v, $\mathrm{cm}^{-1}$ ): $1752(\mathrm{C}=0)$ (ester), $1598(\mathrm{C}=\mathrm{C})$ (unsaturated), $1368\left(\mathrm{CH}_{3}\right) .{ }^{1} \mathrm{H}$ NMR (300 MHz, DMSO-d6, $\delta, \mathrm{ppm}): 2.31\left(\mathrm{~s}, 6 \mathrm{H}, \mathrm{CH}_{3}\right), 7.01-8.39$ (m, 8H, Ar-H). MS (EI, $m / z(\%)): 350\left(\mathrm{M}^{+}, 89\right)$. Anal. calcd. for $\mathrm{C}_{18} \mathrm{H}_{14} \mathrm{~N}_{4} \mathrm{O}_{4}$ : C, 61.71; H, 4.03; N, 15.99; Found: C, 61.69; H, 3.98; N, $15.92 \%$.

\subsubsection{Synthesis of $(1,2,4,5$-tetrazine-3,6-diyl)bis(4,1- phenylene) bis(phenylcarbamate) (11)}

A mixture of 3,6-bis-phenolyl-1,2,4,5-tetrazine (2.66 g, 0.01 mol) 1 and phenylisocyanate (2.38 g, $0.02 \mathrm{~mol}) 10$ in $100 \mathrm{~mL}$ of dry DMF. The flask was then submerged into a $50{ }^{\circ} \mathrm{C}$ oil bath and magnetic stirring and the reaction was held at $50{ }^{\circ} \mathrm{C}$ for approximately $24 \mathrm{~h}$ when the reaction was stopped and the DMF was removed by rotary evaporation. The resulting precipitate was recrystallized from DMF-EtOH $(5: 15, v: v)$ to give final product 11. ${ }^{13} \mathrm{C}$ NMR spectra for $\mathbf{1 1}$ could not be recorded. This was due to the poor solubility of the isolated products in the NMR solvents trialled (Scheme 1).

(1,2,4,5-Tetrazine-3,6-diyl)bis(4,1-phenylene)bis(phenyl carbamate) (11): Color: Purple. Yield: 92\%. M.p.: > $300{ }^{\circ} \mathrm{C}$. FTIR (KBr, v, cm-1): $3110(\mathrm{NH})$ (carbamate), $1715(\mathrm{C}=0)$ (carbamate), $1595(\mathrm{C}=\mathrm{C})$ (unsaturated), 1164 (C-O) (carbamate). 


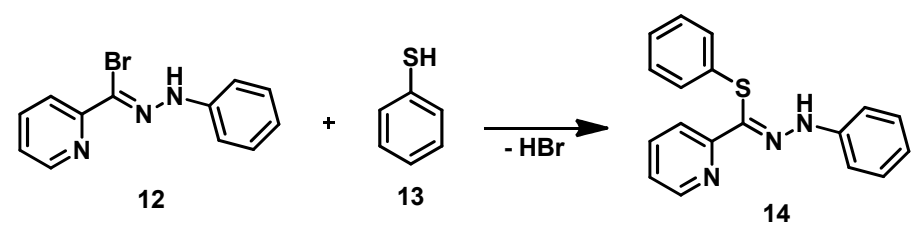

Scheme 2<smiles>CC(=O)/C(Cl)=N\N[Ga]</smiles>

Scheme 3

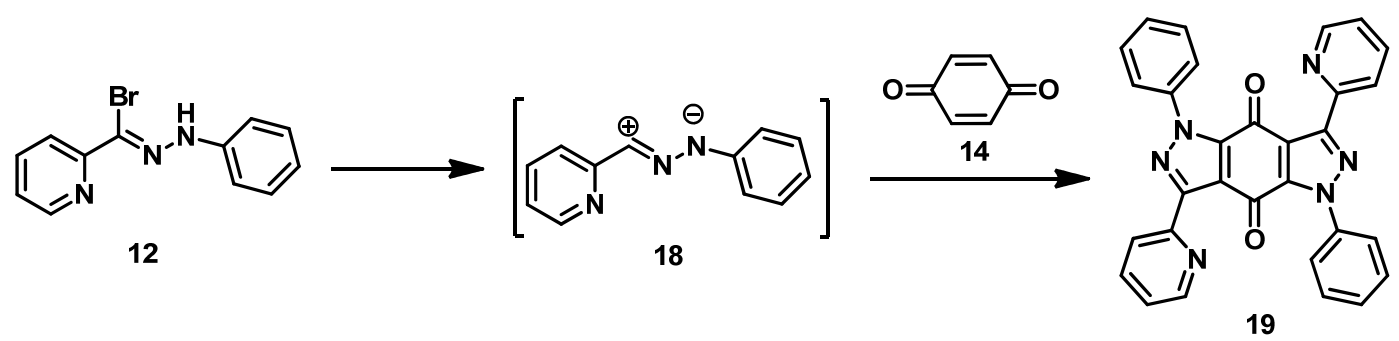

Scheme 4

${ }^{1} \mathrm{H}$ NMR (300 MHz, DMSO- $\left.d_{6}, \delta, \mathrm{ppm}\right): 6.41-8.40(\mathrm{~m}, 18 \mathrm{H}$, Ar-H), 10.41 (s, 2H, NH). MS (EI, $m / z(\%)): 504\left(\mathrm{M}^{+}, 62\right)$. Anal. calcd. for $\mathrm{C}_{28} \mathrm{H}_{20} \mathrm{~N}_{6} \mathrm{O}_{4}$ : C, 66.66; H, 4.00; N, 16.66. Found: C, 66.41; H, 3.98; N, $16.71 \%$.

\subsubsection{Synthesis of (Z)-Phenyl N'-phenylpyridine-2-carbo hydrazonothioate (14)}

A mixture of 1-\{bromo(pyridine-2-yl)methylene\}-2phenylhydrazine (2.75 g, $10 \mathrm{mmol}) \mathbf{1 2}$ and the appropriate of thiophenol (1.10 g, $10 \mathrm{mmol}) \mathbf{1 1}$ in pyridine or EtONa $(20 \mathrm{~mL})$ was stirred at room temperature for $15 \mathrm{~h}$. The reaction mixture was then poured onto ice-cold hydrochloric acid with stirring. The solid that precipitated was collected. The resulting solids filtered, washed with water and recrystallized from $\mathrm{MeOH}$ (Scheme 2).

(Z)-Phenyl N'-phenylpyridine-2-carbohydrazonothioate (14): Color: Yellow brown. Yield: $62 \%$. M.p.: $75^{\circ} \mathrm{C}$. FT-IR (KBr, $v, \mathrm{~cm}^{-}$ 1): $3189(\mathrm{NH}), 1618(\mathrm{C}=\mathrm{N}) .{ }^{1} \mathrm{H}$ NMR (300 MHz, DMSO- $d_{6}, \delta$, ppm): 7.16-8.08 (m, 14H, Ar-H, pyrdinyl), 10.48 (s, 1H, NH). ${ }^{13} \mathrm{C}$ NMR (75 MHz, DMSO- $\left.d_{6}, \delta, \mathrm{ppm}\right): 112.9,116.6,122.1,124.3$, 127.76, 128.45, 129.9, 132.1, 136.9, 133.7, 143.8, 149.5, 151.1, 154.5. MS (EI, $m / z(\%)): 305\left(\mathrm{M}^{+}, 60\right)$. Anal. calcd. for $\mathrm{C}_{18} \mathrm{H}_{15} \mathrm{~N}_{3} \mathrm{~S}$ : C, 70.79; H, 4.95; N, 13.76. Found: C, 70.63; H, 4.94; $\mathrm{N}, 13.81 \%$.

\subsubsection{Synthesis of $(1 Z, 2 E)-2$-benzylidenehydrazinecarbo hydrazonic (Z)-2-oxo- $N$ '-(p-tolyl)propanehydrazonic thioanhydride (17)}

1-(2-p-Tolylhydrazono)-1-chloropropan-2-one (0.21 g, 10 mmol) 15 and phenylmethylene carbonothioic dihydrazide 16 in ethanol $(40 \mathrm{~mL})$ was refluxed for 30 minutes. The reaction mixture was cooled and solid formed was collected and recrystallized from DMF-EtOH $(5: 15, v: v)$ (Scheme 3).

(1Z,2E)-2-benzylidenehydrazinecarbohydrazonic (Z)-2-oxo$N^{\prime}$-(p-tolyl)propanehydrazonic thioanhydride (17): Color: Yellow. Yield: 95\%. M.p.: $215{ }^{\circ} \mathrm{C}$. FT-IR (KBr, v, $\left.\mathrm{cm}^{-1}\right): 3098$ $(=\mathrm{NH}), 1595(\mathrm{C}=\mathrm{N}), 1316\left(\mathrm{CH}_{3}\right) .{ }^{1} \mathrm{H}$ NMR $\left(300 \mathrm{MHz}, \mathrm{DMSO}-d_{6}, \delta\right.$, ppm): $2.20\left(\mathrm{~s}, 3 \mathrm{H}, \mathrm{CH}_{3}\right), 2.39\left(\mathrm{~s}, 3 \mathrm{H}, \mathrm{CH}_{3}\right), 5.85\left(\mathrm{~s}, 2 \mathrm{H}, \mathrm{NH}_{2}\right)$, 7.08-7.81 (m, 10H, Ar-H and =CH), $10.06(\mathrm{~s}, 1 \mathrm{H}, \mathrm{NH}), 10.67(\mathrm{~s}$, $1 \mathrm{H}, \mathrm{NH})$. MS (EI, $m / z(\%))$ : $368\left(\mathrm{M}^{+}, 11\right)$. Anal. calcd. for $\mathrm{C}_{18} \mathrm{H}_{20} \mathrm{~N}_{6} \mathrm{OS}: \mathrm{C}, 58.68 ; \mathrm{H}, 5.47$; N, 22.81. Found: C, 58.61; H, 5.42; N, $22.79 \%$.

\subsubsection{Synthesis of 1,5-diphenyl-3,7-di(pyridin-2-yl)pyrazolo [3,4-f]indazole-4,8(1H,5H)-dione (19)}

To an oven-dried round bottom flask was added 1,4quinone $(0.54 \mathrm{~g}, 5 \mathrm{mmol}) \mathbf{1 4}$ and 1 -\{bromo(pyridine-2yl)methylene $\}$-2-phenylhydrazine $(2.75 \mathrm{~g}, 10 \mathrm{mmol}) 12$ and 20 $\mathrm{mL}$ dry chloroform and $4 \mathrm{~mL}$ DMF in the presence of excess triethylamine $(1.52 \mathrm{~g}, 15 \mathrm{mmol})$. The round bottom flask was attached to a reflux condenser. The reaction mixture solution was heated to reflux for $12 \mathrm{~h}$. The cold reaction mixture was then poured onto ice-cold hydrochloric acid with stirring. The solid that precipitated was collected, washed with water to give final product 19, and dried to open air. The structure was elucidated on the basis of spectral data. Deep green solid recrystallized from $\mathrm{MeOH}$ (Scheme 4).

1,5-diphenyl-3,7-di(pyridin-2-yl)pyrazolo[3,4-f]indazole4,8(1H,5H)-dione (19): Color: Deep green. Yield: 85\%. M.p.: 205 ${ }^{\circ} \mathrm{C}$. FT-IR $\left(\mathrm{KBr}, v, \mathrm{~cm}^{-1}\right)$ : $3101(\mathrm{Ar}-\mathrm{H}), 1650(\mathrm{C}=0), 1604(\mathrm{C}=\mathrm{N})$, 1550 (pyridiny), $1488(\mathrm{C}=\mathrm{C}), 1157(\mathrm{~N}-\mathrm{N}) .{ }^{1} \mathrm{H}$ NMR $(300 \mathrm{MHz}$, DMSO- $\left.d_{6}, \delta, \mathrm{ppm}\right): 6.89-8.74(\mathrm{~m}, 18 \mathrm{H}, \mathrm{Ar}-\mathrm{H}$ and pyrdinyl). MS (EI, $m / z(\%)$ ): $494\left(\mathrm{M}^{+}, 28\right)$. Anal. calcd. for $\mathrm{C}_{30} \mathrm{H}_{18} \mathrm{~N}_{6} \mathrm{O}_{2}$ : C, 72.87; H, 3.67; N, 16.99. Found: C, 72.93; H, 3.59; N, 16.84\%. 
<smiles>Cl/C(=N\Nc1ccccc1)c1ccc(/C(Cl)=N/Nc2ccccc2)cc1</smiles>

20

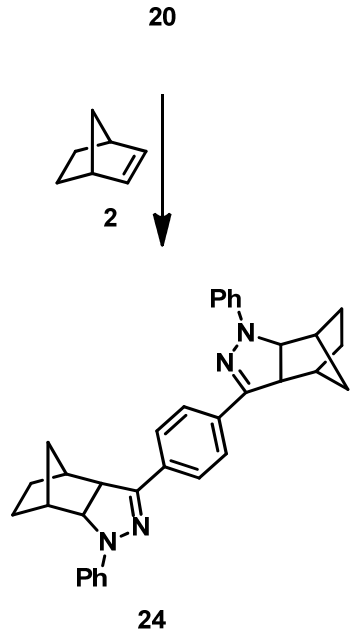

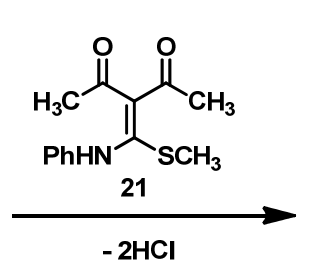

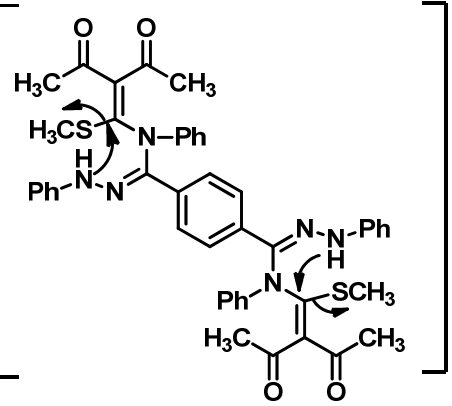

22<smiles></smiles>

23

Scheme 5

2.2.7. Synthesis of 3,3'-(3,3'-(1,4-phenylene)bis(1,4-diphenyl1H-1,2,4-triazole-3(4H)-yl-5(4H)-ylidene))bis(pentane-2,4dione) (23)

To a mixture ketene N,S-acetal $(2.49 \mathrm{~g}, 10 \mathrm{mmol}) 21$ and bis-hydrazonoyl dichlorides (1.92 g, $5 \mathrm{mmol}$ ) 20 in ethanol ( 30 $\mathrm{mL})$ and DMF $(10 \mathrm{~mL})$ was added triethylamine $(5 \mathrm{mmol})$ and the mixture was refluxed till methanethiol ceased to evolve 4-6 h. The precipitate that was formed was filtered off and crystallized from DMF:EtOH mixture $(5: 15, v: v)$ to give 3,3'bis(1,2,4-triazole) derivative $\mathbf{2 3}$ (Scheme 5).

3,3'-(3,3'-(1,4-Phenylene) bis(1,4-diphenyl-1H-1,2,4-triazole3(4H)-yl-5(4H)-ylidene))bis(pentane-2,4-dione) (23): Color: Brown. Yield: 40\%. M.p.: $200{ }^{\circ} \mathrm{C}$. FT-IR (KBr, $\left.v, \mathrm{~cm}^{-1}\right): 1715$ $(\mathrm{C}=0) .{ }^{1} \mathrm{H}$ NMR $\left(300 \mathrm{MHz}, \mathrm{DMSO}-d_{6}, \delta, \mathrm{ppm}\right): 2.06(\mathrm{~s}, 12 \mathrm{H}$, $\left.4 \mathrm{CH}_{3}\right), 6.82-8.11(\mathrm{~m}, 24 \mathrm{H}, \mathrm{ArH})$. MS (EI, $\left.m / z(\%)\right): 712\left(\mathrm{M}^{+}, 56\right)$. Anal. calcd. for $\mathrm{C}_{44} \mathrm{H}_{36} \mathrm{~N}_{6} \mathrm{O}_{4}$ : C, 74.14; $\mathrm{H}, 5.09 ; \mathrm{N}, 11.79$. Found: $\mathrm{C}$, 74.11; H, 5.14; N, $11.83 \%$.

2.2.8. Reaction of 1-((3aR,7aS)-1-phenyl-3a,4,5,6,7,7ahexahydro-1H-4,7-methanoindazol-3-yl)-4-((3aS,4S, 7R, 7aR)-1-phenyl-3a,4,5,6,7,7a-hexahydro-1H-4,7methanoindazol-3-yl)benzene (24)

A mixture of 4-[N,N $N^{\prime}$-diphenyl(bis-hydrazonoyl dichlorides)]benzene $(1.92 \mathrm{~g}, 5 \mathrm{mmol}) \mathbf{2 0}$ and bicycle [2.2.1] hept-2-ene ( $0.94 \mathrm{~g}, 10 \mathrm{mmol}) 2$ in DMF $(20 \mathrm{~mL})$ was boiled under reflux for $5 \mathrm{~h}$. The cold reaction mixture was then poured onto ice-cold hydrochloric acid with stirring. The solid that precipitated was collected. The resulting solids filtered, washed with water and recrystallized from EtOH (Scheme 45).

1-((3aR,7aS)-1-phenyl-3a,4,5,6,7,7a-hexahydro-1H-4,7methanoindazol-3-yl)-4-((3aS,4S,7R,7aR)-1-phenyl-3a,4,5,6,7,7ahexahydro-1H-4,7-methanoindazol-3-yl)benzene (24): Color: Green yellow. Yield: $71 \%$. M.p.: $320{ }^{\circ} \mathrm{C}$. FT-IR $\left(\mathrm{KBr}, v, \mathrm{~cm}^{-1}\right)$ : $1620(\mathrm{C}=\mathrm{N}) .{ }^{1} \mathrm{H}$ NMR $\left(300 \mathrm{MHz}, \mathrm{DMSO}-d_{6}, \delta, \mathrm{ppm}\right): 1.48(\mathrm{q}, 8 \mathrm{H}$, $\left.\mathrm{CH}_{2}\right), 2.23\left(\mathrm{~d}, 4 \mathrm{H}, \mathrm{CH}_{2}\right), 3.04(\mathrm{p}, 2 \mathrm{H}, \mathrm{CH}), 3.38(\mathrm{~s}, 2 \mathrm{H}, \mathrm{CH}), 4.22$ (s, 2H, CH), 5.34 (s, 2H, CH), 6.65-8.19 (m, 14H, ArH). ${ }^{13} \mathrm{C}$ NMR (75 MHz, DMSO- $d_{6}, \delta, \mathrm{ppm}$ ): 24.1, 27.6, 32.9, 54.1, 68.2, 113.1, 119.7, 121.2, 122.1, 126.3, 130.2, 144.1, 149.2. MS (EI, $m / z$ (\%)): $498\left(\mathrm{M}^{+}, 16\right)$. Anal. calcd. for $\mathrm{C}_{34} \mathrm{H}_{34} \mathrm{~N}_{4}$ : C, 81.89; $\mathrm{H}, 6.87$; $\mathrm{N}, 11.24$. Found: C, 81.83; H, 6.90; N, 11.27\%.

\subsubsection{Synthesis of polypyrazole based on bismalimide (27)}

A suspension of bis-hydrazonoyl dichlorides $(1.53 \mathrm{~g}, 5$ mmol) 25 and bis-maleimide (1.92 g, (5 mmol) 26 in $20 \mathrm{~mL}$ of DMF was heated at $105-110{ }^{\circ} \mathrm{C}$ until a slightly yellow solution was formed. The obtained solution was flashed with $\mathrm{N}_{2}$ during $40 \mathrm{~min}$, cooled to $75{ }^{\circ} \mathrm{C}$, and stirred for $43 \mathrm{~h}$. Cooling to the ambient temperature interrupted the reaction, and the solution was dropped into $100 \mathrm{~mL}$ of water. The obtained polymer adduct $\mathbf{2 7}$ was filtered off, and after reprecipitation from DMF into ethanol, the polymer was dried in a vacuum at ambient temperature (Scheme 6).

Bis-Malimide (27): Color: Yellow brown. Yield: 65\%. FT-IR $\left(\mathrm{KBr}, v, \mathrm{~cm}^{-1}\right): 1705(\mathrm{C}=0), 1555(\mathrm{C}=\mathrm{C}) .{ }^{1} \mathrm{H}$ NMR $(300 \mathrm{MHz}$, DMSO- $\left.d_{6}, \delta, \mathrm{ppm}\right): 3.95\left(\mathrm{~s}, 2 \mathrm{H}, \mathrm{CH}_{2}\right), 4.24(\mathrm{~d}, 1 \mathrm{H}, \mathrm{CH}), 5.19(\mathrm{~s}$, $1 \mathrm{H}, \mathrm{CH}), 6.14-7.79(\mathrm{~m}, 13 \mathrm{H}, \mathrm{Ar}-\mathrm{H}) .{ }^{13} \mathrm{C}$ NMR $(75 \mathrm{MHz}$, DMSO-d6, $\delta$, ppm): 41.9, 44.1, 53.8, 114.4, 116.1, 121.3, 126.9, 127.7, $129.8,131.9,133.6,135.1,137.2,140.9,142.3,142.9,169.9$, 170.1 .

\section{Results and discussion}

Electron-deficient heterocyclic tetrazine have proven to be useful reagents that often participate in well-defined inverse electron demand Diels-Alder reactions with electron-rich dienophiles, providing rapid access to a range of highly substituted heterocyclic systems [23]. We have extended these principles to prepare new pyridiazines by reacting of 3,6-bisphenolyl-1,2,4,5-tetrazine $\mathbf{1}$ with bicycle[2.2.1] hept-2-ene 2 or bicycle[2.2.1]hept-2,5-diene 4 in DMF at room temperature. We use symmetric alkene to help us to give one isolated product. 


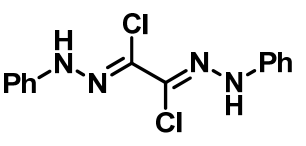

25

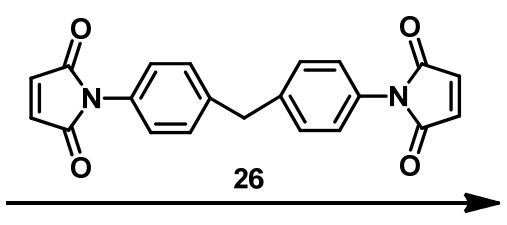

Scheme 6

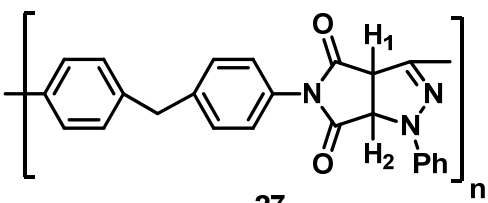

27
The progress of reaction was monitored by disappearance of red color of tetrazine and TLC to give one compound that appeared to be pyridazine as supported by ${ }^{13} \mathrm{C} N M R$ spectroscopy which showed pyridazine in oxidized. Treatment of 3,6-bis-phenolyl-1,2,4,5-tetrazine $\mathbf{1}$ with acetic anhydride $\mathbf{8}$ under heating to give 3,6-bis-phenylacetate-1,2,4,5-tetrazine 9 in good yield. Also, reaction of 3,6-bisphenolyl-1,2,4,5-tetrazine 1 with phenyl isocyanate $\mathbf{1 0}$ to give 3,6-bis-(phenyl phenylcarbamate)-1,2,4,5-tetrazine 11 as shown in Scheme 1. Structures of $\mathbf{3}, \mathbf{6}, \mathbf{9}$ and $\mathbf{1 1}$ were confirmed by elemental analysis and spectra data.

Previously reported arylhydrazonates had great attention and were prepared by reaction of phenols with hydrazonoyl [24]. Thiohydrazonate prepared by treating hydrazonoyl halides 12 or 15 with thiophenol 13 or phenylmethylene carbonothioic dihydrazide 16 to give the final product 14,17 as shown in Scheme 2 and 3.

It is well known that 1,3-dipolar cycloaddtion reactions with 1,4-quinones provide a convenient one step synthesis of condensed heterocyclic quinones [25]. Nitrilimine 18 generated in situ, by the action of triethylamine on the corresponding hydrazonoyl halides $\mathbf{1 2}$, was allowed to react with 1,4-quinone 14 via cycloaddation to afford the final product 19 as shown in Scheme 4. The chemical shifts of pyrazoline protons are analogue to those observed for some closely related pyrazoline derivatives [26] should be appear at 4.64-4.70 ppm but when examined auto oxidation happened.

The required 2-cyano-3-methylthio-3-phenylaminoacrylo nitrile $\mathbf{2 1}$ was prepared by the reaction of malononitrile with phenyl isothiocyanate in DMF in the presence of potassium hydroxide and the resulting thiolate was methylated with methyl iodide to give 2-cyano-3-methylthio-3-phenylamino acrylonitrile 21 [21]. Recently, the synthesis of bis-triazoles [27] from reactions of hydrazonoyl halides with ketene-N,Sacetal was reported. These principles were extended to the reaction of bis-hydrazonoyl dichlorides $\mathbf{2 0}$ with two mole equivalents of $\mathbf{2 1}$ in refluxing DMF:EtOH $(5: 15, v: v)$ in the presence of triethylamine proceeded smoothly to give a product that was identified as 3,3'-bis-(1,2,4-triazole) derivative $\mathbf{2 3}$.

Treatment of bis-hydrazonoyl dichlorides $\mathbf{2 0}$ with bicycle [2.2.1]hept-2-ene $\mathbf{2}$ in DMF/TEA under heating to give final product 24 in good yield.

The structures of the products 23 and $\mathbf{2 4}$ were elucidated on the basis of its microanalysis and spectra data as shown in Scheme 5 (see Experimental).

The synthetic utility of nitrilimine cycloaddition reactions in the most cases deals with construction of low molecular weight five-membered heterocyclic ring systems [21]. The presented paper deals with the synthesis and investigations of new polymers which were prepared via 1,3-dipolar polycycloaddition of bis-hydrazonoyl dichlorides 26 and bismaleimide 27, two maleic protons ( $\mathrm{H} 1$ and $\mathrm{H} 2$ ) can be assigned as multiplet at 4.24 and $5.19 \mathrm{ppm}$. The ${ }^{13} \mathrm{C}$ NMR spectrum showed sharp peaks for the pyrazolidine function at 77.3 and two signals for maelic carbone 74.5 and $42.8 \mathrm{ppm}$. The molecular weight of the polymer could not be recorded. This was due to poor solubility of isolated product in THF. Thermal properties of polymer was investigated by DSC measurements (TG) for polymer was found at $71{ }^{\circ} \mathrm{C}$ and (Tm) was found at $260{ }^{\circ} \mathrm{C}$.

\section{Conclusion}

In summary, the synthesis of novel tetrazine, pyridazines, thiohydrazonate, bis-pyrazole, bis-triazole and polypyrazolinebismaleimide derivatives based on tetrazine and hydrazonoyl halides are reported.

\section{Acknowledgements}

The financial support of this work (Project no: 130178) by the Deanship of Scientific Research, King Faisal University is appreciated

\section{References}

[1]. Boulton, J. A.; McKillop, A. In Comprehensive Heterocyclic Chemistry Pergamon, New York, 1984

[2]. Sauer, J. In Comprehensive Heterocyclic Chemistry II; Katritzky, A. R. Rees, C. W.; Scriven, E. F. V. Pergamon Press Oxford, 1996, pp. 901.

[3]. Pal, M.; Batchu, V. R.; Khanna, S.; Yeleswarapu K. R. Tetrahedron 2002 58, 9933-9940.

[4]. Tisler, M.; Stanovnik, B. In Heterocyclic Chemistry; Katritzky, A. R., Ed.; Academic: San Diego, 1990, pp. 1.

[5]. Coates, W. J.; McKillop, A. Synthesis 1993, 3, 334-342.

[6]. Heinisch, G.; Kopelent, H. In Progress in Medicinal Chemistry, Ellis, G. P., West, G. B., Eds., Elsevier: Amsterdam, 1992, 29, pp. 141-183.

[7]. Ungureanu, M.; Mangalagiu, I.; Grosu, G.; Petrovanu, M. Ann. Pharm. Fr. 1997, 55(2), 69-72.

[8]. Pita, B.; Sotelo, E.; Saurez, M.; Ravina, E.; Ochoa E.; Verdecia, Y.; Novoa, H.; Blaton, N.; de Ranter, C. Peeters O. M., Tetrahedron 2000, 56, 24732479

[9]. Campos, M.; Estevez, I.; Ravina, E.; Orallo, F. Gen. Pharmacol. 1998, 30, 201-207.

[10]. Sayed, A. R. Tetrahedron 2012, 68(13), 2784-2789.

[11]. Sayed, A. R.; Wiggins, J. S. J. Appl. Poly. Sci. 2011, 120(2), 623-630.

[12]. Sayed, A. R. Tetrahedron Lett. 2010, 51, 4490-4493.

[13]. Sayed, A. R.; Wiggins, J. S. Polymer 2008, 49(9), 2253-2259.

[14]. Huisgen, R. Angew. Chem. Int. Ed. Engl. 1963, 10, 565-598.

[15]. Varvounis, G.; Fiamegos, Y.; Pilidis, G. Adv. Heterocycl. Chem. 2001, 80, 75-165.

[16]. Jaroslaw, S. Syn. Comm. 2000, 30(6), 1083-1094.

[17]. Sayed, A. R.; Youssef, M. M. Eur. J. Med. Chem. in review, 2014

[18]. Eweiss, N. F.; Osman, A. J. Heterocycl. Chem. 1980, 17, 1713-1717.

[19]. Badawy, M. A.; Abdelhady, S. A.; Ibrahim, Y. A. Liebigs Ann. Chem. 1990, 4, 393-395.

[20]. Sayed, A. R. Tetrahedron 2013, 69, 5293-5298.

[21]. Finnerty, J.; Mitschke, U.; Wentrup, C. J. Org. Chem. 2002, 67, 10841092.

[22]. Shawali, A. S.; Farag, A. F.; Albar, H. A.; Dawood, K. M. Tetrahedron 1993, 49, 2761-2766.

[23]. Boger, D. L.; Weinreb, S. M. Hetero Diels-Alder Methodology in Organic Synthesis; Academic Press: San Diego, CA, 1987.

[24]. Shawali, A. S.; Hassaneen, H. M. Tetrahedron 1972, 28, 5903-5909.

[25]. Argyropoulos, N. G.; Mentzafos, D.; Terzis, A. J. Heterocylic Chem. 1990, 27, 1983-1988.

[26]. Argyropoulos, N. G.; Coutouli-Argyrop, E. P. Iakobidis Chim. Chron. New Ser. 1964, 13, 161-165.

[27]. Shawali, A. S.; Sayed, A. R.; Zayed, M. M. J. Sulfur Chem. 2011, 32(4), 311-314. 